\title{
Maternal haemoglobin and perinatal outcome
}

\author{
Bharathi Anjanappa*, Radhika BH, Nataraja HG, Renuka Ramaiah, Sathya P
}

Department of Obstetrics \& Gynaecology, ESICMC \& PGIMSR \& MODEL Hospital, Rajajinagar, Bangalore, Karnataka, India

Received: 10 July 2015

Accepted: 14 August 2015

\section{*Correspondence:}

Dr. Bharathi Anjanappa,

E-mail: bharathiworld@rediffmail.com

Copyright: (c) the author(s), publisher and licensee Medip Academy. This is an open-access article distributed under the terms of the Creative Commons Attribution Non-Commercial License, which permits unrestricted non-commercial use, distribution, and reproduction in any medium, provided the original work is properly cited.

\begin{abstract}
Background: Maternal anaemia is common medical disorder in developing countries. WHO defines anaemia as haemoglobin concentration of $\leq 11 \mathrm{~g} / \mathrm{dl}$. However, in developing countries like India, the lower limit is accepted as $<10 \mathrm{~g} / \mathrm{dl}$, because of prevailing socio economic deprivation. Anaemia in pregnancy results in complications such as post-partum haemorrhage, infection, abruption placenta, preeclampsia, increased maternal mortality and morbidity. Also, it has reported to increase the risk of adverse perinatal outcome. The aim of this study was to evaluate the relation between haemoglobin levels in third trimester in pregnant women and adverse perinatal outcome.

Methods: This is a prospective observational study conducted in the department of obstetrics and gynaecology, ESIPGIMSR, Rajajinagar, Bangalore. 218 women were enrolled in the study. All pregnant women with term gestation, singleton pregnancy, with live fetus willing to participate in the study were included. Exclusion criteria included antepartum haemorrhage, anaemia due to acute blood loss, multiple gestation, hypertensive disorders of pregnancy, stillbirths and IUDS. Haemoglobin estimation was done by cyanmethaemoglobin method. Paticipants in the study were divided into 2 groups; those with $\mathrm{Hb}<10 \mathrm{~g} / \mathrm{dl}$ and those with $\mathrm{Hb}>10 \mathrm{~g} / \mathrm{dl}$.

Results: Of 218 women, 69 had anaemia. The prevalence of anaemia was 31.65\%; of which $84 \%$ had mild anaemia, $14.6 \%$ had moderate and only $1.4 \%$ had severe anaemia. Mean Hb levels were $12.04 \%$ among non-anaemic mothers and mean birth weight was $2.89 \mathrm{Kg}$ whereas $9.14 \%, 2.18 \mathrm{~kg}$ in anaemic mothers respectively. In our study, $21 \%$ in anaemic group has birth weight $<2.5 \mathrm{~kg}$ and only $0.06 \%$ in non-anaemic mothers $(\mathrm{p}<0.0012) 3.6$ times higher. The risk of IUGR was 3.77 times higher, low APGAR score at 1 min was 3.8 times higher $(\mathrm{p}<0.0001)$, meconium stained liquor was 2.3 times higher and NICU admissions 2.96 times higher in anaemic mothers than non-anaemic mothers.

Conclusions: Anaemia in pregnancy is one of the causes of poor perinatal outcome. Maternal anaemia is associated with the high risk of low birth weight, IUGR babies, low APGAR scores and NICU admissions and overall increase in perinatal morbidity. Hence proper antenatal care and counseling can reduce occurrence of anaemia in pregnancy.
\end{abstract}

Keywords: Anaemia, Haemoglobin, Perinatal outcome

\section{INTRODUCTION}

Maternal anaemia is common medical disorder in developing countries. Anaemia is defined as reduction in circulating haemoglobin mass below the critical value. WHO defines anaemia as haemoglobin concentration of $\leq 11 \mathrm{~g} / \mathrm{dl}$. Centre for Disease Control (CDC) defines anaemia as haemoglobin $\leq 11 \mathrm{mg} / \mathrm{dl}$ in first and third trimester and $<10 \mathrm{gm} / \mathrm{dl}$ in second trimester. However, in developing countries like India, the lower limit is accepted as $<10 \mathrm{~g} / \mathrm{dl}$, because of prevailing socio economic deprivation. ${ }^{1,2}$ WHO reports the incidence of $35-75 \%$ in developing countries and $18 \%$ in developed countries. Prevalence of anaemia is $43 \%$ in women in developing countries and $12 \%$ in developed countries. In India, it is $88 \% .^{2} 20 \%$ of maternal deaths are directly or 
indirectly related to anaemia. It is estimated that 1.200 million people are anaemic worldwide. ${ }^{2}$ Common causes of anaemia include malnutrition, poor socioeconomic status, parity, lack of education, worm infestation, lack of regular antenatal care.

Anaemia in pregnancy results in complications such as post-partum haemorrhage, infection, abruption placenta, preeclampsia, increased maternal mortality and morbidity. Also, it has reported to increase the risk of adverse perinatal outcome. However, the extent to which maternal haemoglobin affects the perinatal outcome is still uncertain. There is variation in data from different studies on maternal haemoglobin and adverse perinatal outcome. The aim of this study is to evaluate the relation between haemoglobin levels in third trimester in pregnant women and perinatal outcome.

Aims and objectives of the study was to determine the relationship between maternal haemoglobin in third trimester and perinatal outcome.

\section{METHODS}

This is a prospective observational study conducted in the department of obstetrics and gynaecology, ESIPGIMSR, Rajajinagar, Bangalore. 218 women were enrolled in the study. All pregnant women with term gestation, singleton pregnancy, with live fetus willing to participate in the study were included. Exclusion criteria included antepartum haemorrhage, anaemia due to acute blood loss, multiple gestation, hypertensive disorders of pregnancy, stillbirths and IUDS. After obtaining informed consent from all the participants, blood for haemoglobin measurement was taken in third trimester or at the time of delivery. Haemoglobin estimation was done by cyanmethaemoglobin method.

Participants in the study were divided into two groups. Those with haemoglobin $<10 \mathrm{~g} / \mathrm{dl}$ and those having haemoglobin $\geq 10 \mathrm{~g} / \mathrm{dl}$. Patients with hemoglobin $<10 \mathrm{~g} / \mathrm{dl}$ were subdivided into three groups depending on the severity of anaemia. Mild anaemia (>8.1-10 g\%), moderate anaemia $(5.1-8 \mathrm{~g} \%)$ and severe anaemia $(<5$ $\mathrm{g} \%$ ). Maternal haemoglobin $<10 \mathrm{~g}$ was considered as anaemia in this study. All the information regarding gestational age at delivery, complications at delivery, neonatal outcome in terms of birth weight, APGAR score, NICU admission, indication for NICU admission, duration of NICU stay, meconium stained liquor, IUGR, intrapartum death were recorded. Statistical analysis was done using Chi-square test. The resultant $\mathrm{p}$ value was considered statistically significant if less than 0.05 .

\section{RESULTS}

Of 218 women, 98 women were primigravida and 120 women were multigravida, among which, 5 were grand multi $\geq 5$.
Table 1 shows age distribution. Out of 69 anaemic mothers, $42(60.86 \%)$ belonged to $21-25$ years. Seven women were $\leq 20$ years $(10.14 \%)$ and five were $>30$ years (7.24\%).

\section{Table 1: Age distribution.}

\begin{tabular}{|ll|}
\hline \multicolumn{2}{|l|}{ Age distribution } \\
\hline$\leq 20$ (years) & 15 \\
\hline $21-25$ (years) & 110 \\
\hline $26-29$ (years) & 75 \\
\hline$\geq 30$ (years) & 18 \\
\hline
\end{tabular}

In our study, haemoglobin concentration $<10 \mathrm{~g} / \mathrm{dl}$ was considered as anaemia. The lowest range of haemoglobin among anaemic was $6.2 \mathrm{~g} \%$. And the highest range of haemoglobin among non-anaemic was $15.1 \mathrm{~g} \%$. Of 218 women in the study, $149(68.3 \%)$ women were not anaemic and $69(31.65 \%)$ were anaemic. Out of all anaemic patients, $58(84 \%)$ had mild anaemia $\mathrm{Hb}(8.1-$ $10 \mathrm{~g} \%), 10(14.6 \%)$ patients had moderate anaemia $\mathrm{Hb}(5-$ $8 \mathrm{~g} \%)$ and only one patient $(1.4 \%)$ had severe anaemia $(<5 \mathrm{~g} \%)$ (Table 2).

Mean haemoglobin level was $12.04 \%$ among nonanaemic mothers and mean birth weight was $2.89 \mathrm{~kg}$ in this group. Whereas, mean haemoglobin level in anaemic mothers was $9.14 \%$ and mean birth weight was 2.18 in this group (Table 2).

Table 2: Maternal haemoglobin versus fetal weight, $(\mathbf{n}=\mathbf{2 1 8})$.

\begin{tabular}{|c|c|c|c|}
\hline $\begin{array}{l}\text { Maternal } \\
\text { haemoglobin } \\
\text { level }\end{array}$ & $\begin{array}{l}\text { Number of } \\
\text { patients }(\%)\end{array}$ & $\begin{array}{l}\text { Mean birth } \\
\text { weight }\end{array}$ & $\begin{array}{l}\text { Mean } \\
\text { haemoglobin }\end{array}$ \\
\hline$\geq 10 \mathrm{~g} \%$ & $149(68.3 \%)$ & $2.89 \mathrm{~kg}$ & $12.04 \%$ \\
\hline $8.1-10 \mathrm{~g} \%$ & $58(84 \%)$ & \multirow{3}{*}{$2.18 \mathrm{~kg}$} & \multirow{3}{*}{$9.14 \%$} \\
\hline $5-8 \mathrm{~g} \%$ & $10(14.6 \%)$ & & \\
\hline$<5 \mathrm{~g} \%$ & $1(1.4 \%)$ & & \\
\hline
\end{tabular}

Table 3: Maternal haemoglobin v/s birth weight.

\begin{tabular}{|lll|}
\multicolumn{1}{|c}{} & $\begin{array}{l}\text { Birth weight } \\
<2.5\end{array}$ & $\begin{array}{l}\text { Birth weight } \\
>2.5\end{array}$ \\
\hline $\begin{array}{l}\text { Haemoglobin } \\
<10 \mathrm{~g} \%(\mathrm{n}=69)\end{array}$ & $15(21.73 \%)$ & $54(78.2 \%)$ \\
\hline $\begin{array}{l}\text { Haemoglobin } \\
\geq 10 \mathrm{~g} \%(\mathrm{n}=149)\end{array}$ & $9(6.04 \%)$ & $140(93.9 \%)$ \\
\hline
\end{tabular}

$\mathrm{p}=0.0012, \mathrm{RR}=3.5990,95 \%$ C.I. 1.6572 to 7.8164

The risk of low birth weight was 3.6 times higher among anaemic mothers, which is statistically significant $(\mathrm{p}=0.0012$ ) (Table 3 and 4) and IUGR babies were 3.77 times more seen in the anaemic mothers (Table 4). 
Table 4: Neonatal outcome and maternal haemoglobin levels.

\begin{tabular}{|c|c|c|c|c|}
\hline Variable & $\begin{array}{l}\text { Non anaemic } \\
(\mathrm{n}=\mathbf{1 4 9})\end{array}$ & $\begin{array}{l}\text { Anaemic } \\
(\mathrm{n}=69)\end{array}$ & p & $\begin{array}{l}\text { Relative risk } \\
\text { ( } 95 \% \text { confidence interval) }\end{array}$ \\
\hline $\begin{array}{l}\text { LBW-yes }(n=24) \\
\text { No. }\end{array}$ & $\begin{array}{l}9 \\
140\end{array}$ & $\begin{array}{l}15 \\
54\end{array}$ & 0.0012 & $\begin{array}{l}3.5990 \\
(1.6572-7.8164)\end{array}$ \\
\hline $\begin{array}{l}\text { IUGR-yes }(\mathrm{n}=11) \\
\text { No. }\end{array}$ & $\begin{array}{l}4 \\
145\end{array}$ & $\begin{array}{l}7 \\
62\end{array}$ & 0.0292 & $\begin{array}{l}3.7790 \\
(1.1440-12.4826)\end{array}$ \\
\hline $\begin{array}{l}\text { Low APGAR }<6 \text { at } 1 \text { min-yes }(n=50) \\
\text { No. }\end{array}$ & $\begin{array}{l}18 \\
131\end{array}$ & $\begin{array}{l}32 \\
37\end{array}$ & $<0.0001$ & $\begin{array}{l}3.8390 \\
(2.3238-6.3421)\end{array}$ \\
\hline $\begin{array}{l}\text { MSL-yes }(n=26) \\
\text { No. }\end{array}$ & $\begin{array}{l}11 \\
138\end{array}$ & $\begin{array}{l}13 \\
56\end{array}$ & 0.0227 & $\begin{array}{l}2.3394 \\
(1.213-4.023)\end{array}$ \\
\hline $\begin{array}{l}\text { NICU admission-yes }(\mathrm{n}=19) \\
\text { No. }\end{array}$ & $\begin{array}{l}11 \\
138\end{array}$ & $\begin{array}{l}8 \\
61\end{array}$ & 0.0136 & $\begin{array}{l}2.96 \\
(1.2504-7.0509)\end{array}$ \\
\hline
\end{tabular}

18 out of 69 babies in anaemic group had low APGAR scores, $<6$ at one minute, compared to 32 of 149 babies in non-anaemic mothers $(\mathrm{p}<0.0001)$.

Babies born to anaemic mothers required NICU care more than those of non-anaemic mothers. NICU admissions was 2.96 times more common in anaemic group ( $\mathrm{p}<0.0136)$.

Meconium stained liquor was also more in anaemic mothers $(\mathrm{p}<0.0227)$ with RR 2.34 .

\section{DISCUSSION}

Anaemia in pregnancy is an important public health concern worldwide. WHO reports the incidence of $35 \%$ to $75 \%$ in developing countries and $18 \%$ in developed countries. Prevalence of anaemia is $43 \%$ in women in developing countries and $12 \%$ in developed countries. In India, it is $88 \% .^{1-4}$

Prevalence of anaemia in our study is $31.65 \%$, of which $84 \%$ had mild anaemia, $14.6 \%$ had moderate type and only $1.4 \%$ had severe anaemia. The prevalence of anaemia was slightly low in our study compared to study by Shukat et al., 5 were $47 \%$ women were anaemic and Tuladhar et al. ${ }^{6}$ reported incidence of $41.1 \%$ among them $71.4 \%$ had mild anaemia, $24.4 \%$ had moderate anaemia and $4.2 \%$ had severe anaemia. Rana et al. ${ }^{1}$ reported prevalence of anaemia of $46.2 \%$, out of which $99.5 \%$ had mild anaemia, $0.5 \%$ moderate anaemia and no case of severe anaemia. The low prevalence in our study could be due to adequate antenatal care and adequate diet and iron supplementation.

In this study, mean haemoglobin level was $12.04 \%$ among non- anaemic mothers and mean birth weight was $2.89 \mathrm{~kg}$ in this group. Whereas, mean haemoglobin level in anaemic mothers was $9.14 \%$ and mean birth weight was 2.18 in this group (Table 2). Similar findings were reported by Rana et al. ${ }^{1}$ (mean $\mathrm{Hb}$ con was $11.5 \%$, weight - $2.9 \mathrm{~kg}$ in non-anaemic and $9.2 \%, 2.6 \mathrm{~kg}$ in anaemic mothers respectively) and Nahum et al. ${ }^{7}$ (with mean $\mathrm{Hb}$ con of $11.6 \mathrm{~g} \%$ and mean birth weight of $3.5 \mathrm{~kg}$ in nonanaemic group).

In this study, $21 \%$ in anaemic group had birth weight $<2.5 \mathrm{~kg}$ and $0.06 \%$ in non-anaemic group were low birth weight babies. This difference was statistically significant $(\mathrm{p}=0.0012)$. The risk of low birth weight was 3.6 times higher among anaemic mothers. Godfrey et al. ${ }^{8}$ also suggested a relationship between maternal haemoglobin and low birth weight. Rana et al. ${ }^{1}$ showed 6.8 times higher risk of lbw babies among anaemic mothers. Ahmad et al., ${ }^{9}$ Bakhtiar et al., ${ }^{10}$ Lone FW et al. ${ }^{11}$ showed 1.8, 1.8 and 1.9 times higher risk of lbw babies among anaemic mothers.

Our data also showed the association of maternal anaemia in pregnancy with increased risk of low APGAR scores at one min, Meconium stained liquor and NICU admissions. The most common indication for NICU admission being, respiratory distress due to low APGAR scores. There was no neonatal deaths $s$ in our study. Bakhtiar et al., ${ }^{10}$ Lone FW et al., ${ }^{11}$ Bhalerao A et al. ${ }^{12}$ reported low APGAR score at $1 \mathrm{~min} 1.7,1.8,1.8$ times higher risk in anaemic mothers than non-anaemic mothers.

Presentation for antenatal care in third trimester is common in our country. Since the demand for micronutrient is maximum in third trimester, this could be one factor underlying high prevalence of anaemia.

\section{CONCLUSIONS}

Anaemia in pregnancy is one of the causes of poor perinatal outcome. Maternal Anaemia is associated with the high risk of low birth weight, IUGR babies, low APGAR scores and NICU admissions and overall increases perinatal mortality and morbidity. Hence proper antenatal care and counselling can reduce the occurrence of anaemia in pregnancy.

\section{ACKNOWLEDGEMENTS}

I acknowledge to my teacher, all my patients, postgraduate students, and staff. 
Funding: No funding sources

Conflict of interest: None declared

Ethical approval: The study was approved by the institutional ethics committee

\section{REFERENCES}

1. Rana SS, Sharma S, Chand A, Malla R. Relationship between maternal haemoglobin and fetal weight. NJOG. 2013;8(1):37-40.

2. WHO. World health statistics quarterly. Geneva: WHO; 1980: 197-224.

3. UNICEF. Reduction of low birth weight, a South Asia priority. Kathmandu: UNICEF Rosa; 2002.

4. Francis S, Nayak S. Maternal haemoglobin level and its association with pregnancy outcome among mothers. NUJHS. 2013;3(3):96-110.

5. Shaukat M, Zaheen A, Zaanam Q, Sheikh GA. Maternal anaemia, perinatal morbidity and mortality. J Pak Paed Assoc. 2002;80:88-98.

6. Tuladhar H. Anaemia in adolescent pregnancy. JNMC. 2000;2(1):19-21.
7. Nahum GG, Stanislaw H. High altitude exposure during pregnancy and low birth weight. J Rep Med. 2004;49(4):297-305.

8. Godfrey KM, Reman WG, Barker DJP, Osmond C. The effect of maternal anemia and iron deficiency on the relation of fetal weight to placental weight. $\mathrm{Br} \mathbf{J}$ Obstet Gynaecol.1991;98:886.

9. Ahmad MO, Kalsoom U, Sughra U, Hadi U, Imran M. Effect of maternal anaemia on birth weight. J Ayub Med Coll Abbottabad. 2011;23(1):77-9.

10. Bakhtiar UJ, Khan Y, Nasar R. Relationship between maternal haemoglobin and perinatal outcome. Rawal Med J. 2007;32(2):102-4.

11. Lone FW, Qureshi RN, Emanuel F. Maternal anaemia and its impact on perinatal outcome. Trop Med Int Health. 2004;9(4):486-90.

12. Bhalerao A, Kawthalkar A, Ghike S, Joshi S. Anaemia during pregnancy: most preventable yet most prevalent. JSAFOG. 2011;3(2):75-7.

Cite this article as: Anjanappa B, Radhika BH, Nataraja HG, Ramaiah R, Sathya P. Maternal haemoglobin and perinatal outcome. Int J Reprod Contracept Obstet Gynecol 2015;4:1335-8. 